\title{
Physiological effects of nitrogen starvation in an anaerobic batch culture of Saccharomyces cerevisiae
}

\author{
Ulrik Schulze, ${ }^{1} \dagger$ Gunnar Lidén, ${ }^{2}$ Jens Nielsen ${ }^{1}$ and John Villadsen ${ }^{1}$ \\ Author for correspondence: Ulrik Schulze. Tel: +454525 2669. Fax: +4545884148. \\ e-mail: us@ibt.dtu.dk
}

1 Center for Process

Biotechnology,

Department of

Biotechnology, Technical

University of Denmark,

Building 223, DK-2800

Lyngby, Denmark

2 Department of Chemical Reaction Engineering, Chalmers University of Technology, S-41296 Goteborg, Sweden

\begin{abstract}
The effects of nitrogen starvation on the anaerobic physiology of Saccharomyces cerevisiae were studied in cells cultivated in a bioreactor. The composition of the mineral medium was designed such that the nitrogen source became depleted while there was still ample glucose left in the medium. The culture was characterized by acoustic gas analysis, flow injection analysis and HPLC analysis of extracellular substrates and metabolites. During the cultivation, the macromolecular composition of the cells was analysed with respect to the cellular content of RNA, protein, trehalose and glycogen. During exponential growth under anaerobic conditions, the maximum specific growth rate $\left(\mu_{\max }\right)$ of S. cerevisiae CBS $8066\left(0.46 \mathrm{~h}^{-1}\right)$ was identical to the $\mu_{\max }$ determined under aerobic conditions. Depletion of ammonium in the medium led to an abrupt decrease in the flux through glycolysis. Subsequently, a continuous decrease in the carbon dioxide evolution rate, caused by catabolite inactivation of the hexose-transport system, was observed. The apparent halflife of the transport system under nitrogen starvation was $13 \mathrm{~h}$. During the exponential growth phase, the cellular content of RNA and protein was $15 \%$ $(w / w)$ and $60 \%(w / w)$, respectively. At the end of the cultivation where the cells had been starved of nitrogen for $18 \mathrm{~h}$, the cellular content of RNA and protein had decreased to $4 \%(w / w)$ and $22 \%(w / w)$, respectively. The intracellular carbohydrate content increased dramatically as trehalose and glycogen accumulated to final concentrations of $7 \%(w / w)$ and $25 \%(w / w)$, respectively. Glycerol formation during nitrogen starvation was higher than that accounted for by the formation of organic acids, suggesting a protein turnover of approximately $6 \% \mathrm{~h}^{-1}$. The growth energetics of S. cerevisiae CBS 8066 also changed as a result of nitrogen starvation, and $Y_{x A T P}$ was observed to increase from $80 \mathrm{mmol} \mathrm{g}^{-1}$ during the exponential growth phase to more than $130 \mathrm{mmol} \mathrm{g}^{-1}$ towards the end of the cultivation. The presented results illustrate the effect of nitrogen starvation on glycerol formation, protein turnover, catabolite inactivation of the sugar-transport system, the cellular composition, the cell cycle and growth energetics.
\end{abstract}

Keywords: Saccharomyces cerevisiae, anaerobic batch culture, nitrogen starvation, intracellular metabolites, growth energetics

\section{INTRODUCTION}

Although Saccharomyces cerevisiae is one of the few yeasts

†Present address: Department of Chemical Engineering, Massachusetts Institute of Technology, Cambridge, MA 02139, USA.

Abbreviations: CER, carbon dioxide evolution rate; EMP, EmbdenMeyerhof-Parnas; RSD, relative standard deviation. capable of good anaerobic growth (Visser et al., 1990), the anaerobic physiology of this micro-organism has not gained as much attention as the aerobic, even though it is of great industrial importance, e.g. in the production of ethanol and beverages like beer and wine. The focus of previous studies of the anaerobic physiology of $S$. cerevisiae has been on the basic physiology (Schatzmann, 1975; Verduyn et al., 1990a; Visser et al., 1994, 1995) and 


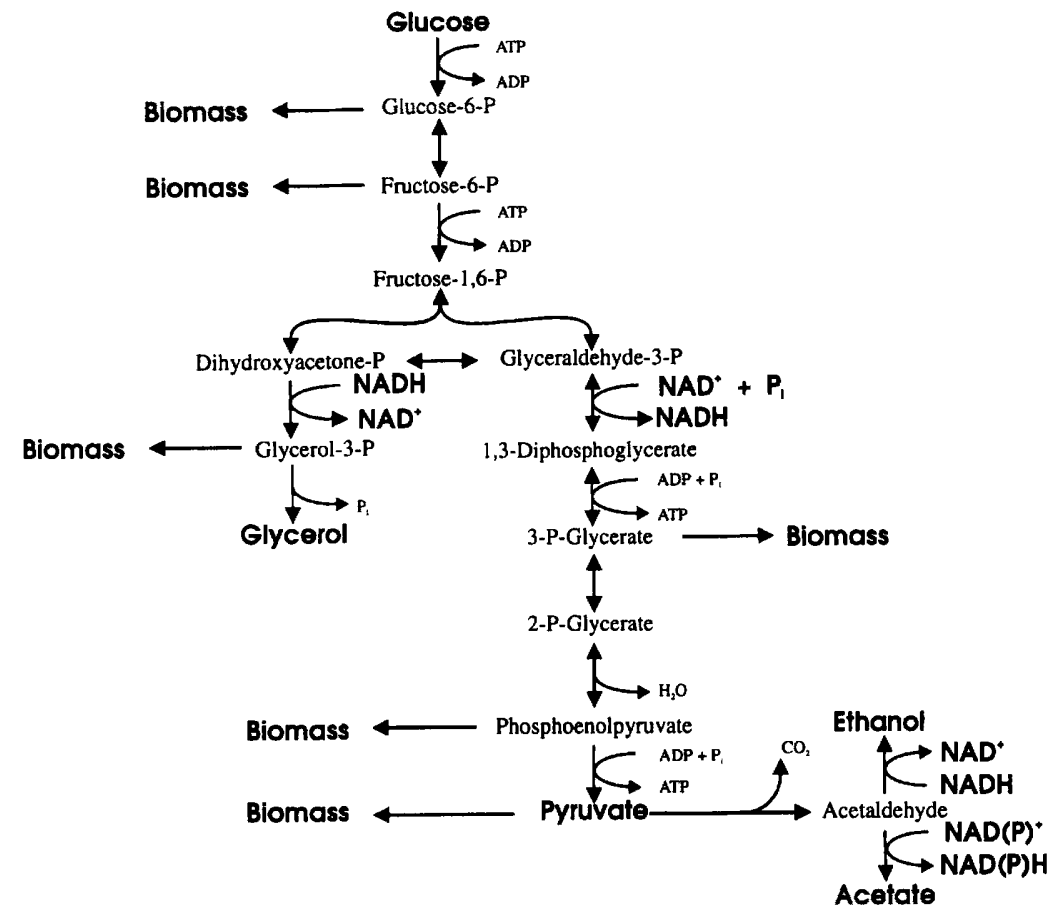

Fig. 1. Major catabolic pathways in $S$. cerevisiae for the metabolism of glucose under anaerobic conditions. growth energetics (Verduyn et al., 1990b) under conditions of glucose limitation. Limitation by other nutrients, e.g. nitrogen, has not been studied, despite the fact that these kinds of limitations or starvations occur in industrial processes and are known to induce profound changes in the metabolism of cells. Nitrogen limitation leads to changes in the grown energetics of both bacteria (Benthin et al., 1994) and yeast (Larsson et al., 1993). The macromolecular composition of cells will change as a result of nitrogen starvation (Johnston et al., 1977b; Lillie \& Pringle, 1980; Lagunas \& Ruiz, 1988) and under such conditions aerobically cultivated $S$. cerevisiae accumulates intracellular carbohydrates in the form of glycogen and trehalose (Lillie \& Pringle, 1980; Quain et al., 1981). Nitrogen starvation also leads to catabolite inactivation of the glucose-transport system in S. cerevisiae (Lagunas et al., 1982; Busturia \& Lagunas, 1986), an aspect of the anaerobic yeast physiology which can be a great nuisance to oenology (Salmon, 1989). Nitrogen starvation will eventually cause yeast cells to arrest in the $G_{1}$ portion of the cell cycle (Johnston et al., 1977a; Johnston, 1977), but those cells which have just initiated the DNA division cycle when nitrogen starvation sets in will continue and complete their division cycle with little dependence on continued net cell growth (Johnston et al., 1977b).

The anaerobic conversion of glucose into ethanol by $S$. cerevisiae is redox neutral, i.e. the $\mathrm{NAD}^{+}$consumed initially in the Embden-Meyerhof-Parnas (EMP) pathway is regenerated when ethanol is produced (see Fig. 1). However, when intermediates in the EMP pathway are withdrawn as precursors for synthesis of cellular material, this balance is disturbed since the surplus of NADH produced initially in the EMP pathway is not converted back into $\mathrm{NAD}^{+}$. Thus other processes must exist for the regeneration of $\mathrm{NAD}^{+}$. During anaerobic growth, NADH cannot be oxidized by oxygen but must be disposed of by formation of reduced byproducts such as glycerol (Holzer et al., 1963; Oura, 1977). Anabolism is responsible for the major part of the glycerol production (Lagunas \& Gancedo, 1973; van Dijken \& Scheffers, 1986; Schulze, 1995), but secretion of organic acids like acetic acid, pyruvic acid and especially succinic acid will also require compensatory formation of glycerol (Genevois, 1950, 1961; Oura, 1977). Since nitrogen limitation or starvation affects anabolism, it will also influence the formation of glycerol. Turnover of the cellular protein complement has been observed under conditions of nitrogen starvation (López \& Gancedo, 1979) and this too can be expected to affect glycerol formation.

The objective of the present work was to study the effects of nitrogen starvation on the anaerobic physiology of $S$. cerevisiae. This has been achieved by monitoring the growth and product formation under well-defined conditions in a batch cultivation. A detailed picture has emerged of the cellular composition and the product and byproduct formation. The results illustrate the effects of nitrogen starvation on glycerol formation, protein turnover, catabolite inactivation of the sugar-transport system, the cellular composition, the cell cycle and growth energetics.

\section{METHODS}

Micro-organism and its maintenance. Saccharomyces cerevisiae CBS 8066 was obtained from the Centraal Bureau voor Schimmelcultures (Delft, the Netherlands). The strain was maintained at $4{ }^{\circ} \mathrm{C}$ on yeast extract/peptone/glucose agar plates, monthly prepared from a lyophilized stock kept at 
$-80^{\circ} \mathrm{C}$. The bioreactor was inoculated to an initial biomass concentration of $1 \mathrm{mg} \mathrm{l}^{-1}$ with a preculture grown in unbaffled shake flasks at $30^{\circ} \mathrm{C}$ and 100 r.p.m. for 24 h.

Media. The yeast was cultivated in a mineral medium prepared according to Verduyn et al. (1990a) except for the following changes: the concentration of $\left(\mathrm{NH}_{4}\right)_{2} \mathrm{SO}_{4}$ was $0.64 \mathrm{~g} \mathrm{l}^{-1}$, the concentrations of all vitamins were doubled and glucose was added as sole carbon source to a concentration of $50 \mathrm{~g} \mathrm{l}^{-1}$. Growth of $S$. cerevisiae under anaerobic conditions requires the supplementary addition to the medium of ergosterol and unsaturated fatty acids, typically in the form of Tween 80 (Andreasen \& Stier, 1953, 1954). Ergosterol and Tween 80 were dissolved in $96 \%(\mathrm{v} / \mathrm{v})$ ethanol and the solution was autoclaved at $121{ }^{\circ} \mathrm{C}$ for $5 \mathrm{~min}$. The final concentrations of ergosterol and Tween 80 in the medium were $15 \mathrm{mg} \mathrm{l}^{-1}$ and $660 \mathrm{mg} \mathrm{l}^{-1}$, respectively. To prevent foaming, $75 \mu \mathrm{l}$ antifoam $1^{-1}$ (Sigma; A-5551) was added to the medium.

Cultivation conditions. The anaerobic batch fermentations were performed at $30^{\circ} \mathrm{C}$ and at a stirring speed of 500 r.p.m. in a bioreactor manufactured in-house with a working volume of 5 l. $\mathrm{pH}$ was kept constant at 5.00 by addition of $2 \mathrm{M} \mathrm{KOH}$. The bioreactor was equipped with an off-gas condenser cooled to $2{ }^{\circ} \mathrm{C}$. The bioreactor was continuously sparged with nitrogen gas containing less than 5 p.p.m. oxygen, obtained by passing nitrogen gas of a technical quality (AGA 3.8), containing less than 100 p.p.m. oxygen, through a column $(250 \times 30 \mathrm{~mm})$ filled with copper turnings and heated to $350{ }^{\circ} \mathrm{C}$. The column was regenerated daily by sparging it with hydrogen (AGA 3.6) for 2 min. A mass flow controller (Bronkhorst HiTec F201C) was used to keep the gas flow into the bioreactor constant at $0.751 \mathrm{~min}^{-1}$. Norprene tubing (Cole-Parmer Instruments) was used throughout in order to minimize diffusion of oxygen into the bioreactor.

Determination of dry weight. Dry weight was determined gravimetrically using nitrocellulose filters (pore size $0.45 \mu \mathrm{m}$; Gelman Sciences). The filters were predried in a microwave oven (Moulinex FM B 935Q) for 10 min. A known volume of culture liquid was filtered and the filter was washed with an equal volume of demineralized water, followed by drying in a microwave oven for $15 \mathrm{~min}$. The relative standard deviation (RSD) was less than $1.5 \%$ based on triple determinations $(n=3)$.

Analysis of metabolites. Cell-free samples were obtained directly from the bioreactor through a capillary connected to a $0.45 \mu \mathrm{m}$ filter. Samples were subsequently stored at $-40^{\circ} \mathrm{C}$. Glucose, ethanol, glycerol, acetic acid, pyruvic acid and succinic acid were determined by HPLC using an HPX-87H Aminex ion exclusion column (RSD $<0.6 \%, n=3$ ). The column was eluted at $60^{\circ} \mathrm{C}$ with $5 \mathrm{mM} \mathrm{H}_{2} \mathrm{SO}_{4}$ at a flow rate of $0.6 \mathrm{ml} \mathrm{min}^{-1}$ Pyruvic acid and acetic acid were determined with a Waters 486 UV meter at $210 \mathrm{~nm}$, whereas the other metabolites were determined with a Waters 410 refractive index detector. The two detectors were connected in series with the UV detector first. Ammonium was determined using a flow injection analyser as described by Christensen et al. (1991) ( $\mathrm{RSD}=1 \cdot 0 \%, n=3$ ).

Gas analysis. The carbon dioxide concentration in the off-gas was determined using a Brüel \& Kjær (1308) acoustic gas analyser (Christensen et al., 1995) ( $\mathrm{RSD}=0.02 \%)$. In calculating the carbon dioxide evolution rate (CER), corrections were made for changes in the liquid volume in the bioreactor and changes in the gas flow due to carbon dioxide evolution.

Analysis of intracellular metabolites. Culture liquid was withdrawn from the bioreactor into an ice-cooled beaker. For each analysis, an adequate amount of sample was centrifuged, washed twice with $0.9 \%(\mathrm{w} / \mathrm{w}) \mathrm{NaCl}$ and resuspended in buffer.
Samples were immediately frozen in liquid nitrogen and subsequently stored at $-40^{\circ} \mathrm{C}$. The protein content of whole cells was determined by a modified Biuret method according to Verduyn et al. (1990a) ( $\mathrm{RSD}=2.5 \%, n=3$ ). RNA measurements were determined as described by Benthin et al. (1991b) $(\mathrm{RSD}=2 \cdot 0 \%, n=3)$. Trehalose and glycogen were determined enzymically as previously described (Schulze $e t$ al., 1995) $(\mathrm{RSD}=$ $2.5 \%, n=3$ ).

Enzyme assay. In vitro enzyme activities were determined in freshly prepared cell-free extracts (Postma et al., 1989) at $30^{\circ} \mathrm{C}$, and it was checked that the reaction rate was proportional to the amount of cell-free extract added. Catalase was assayed as described by Verduyn et al. (1984). One unit is defined as the amount of enzyme catalysing the conversion of $1 \mu \mathrm{mol}$ substrate $\mathrm{min}^{-1}$. The specific activity is expressed as units per $\mathrm{mg}$ protein in the cell-free extract as determined by the Lowry method.

Reproducibility. All experiments were repeated at least once and gave results identical to those presented in this paper considering the RSD of the individual analyses (see above).

\section{RESULTS}

\section{Establishment and maintenance of anaerobic conditions}

When studying the anaerobic physiology of $S$. cerevisiae, it is crucial that oxygen is efficiently excluded from the growth environment. In the presence of oxygen, $S$. cerevisiae can generate much more ATP by respiring glucose to carbon dioxide than that generated by substrate-level phosphorylation. In addition, since oxygen can be used to reoxidize $\mathrm{NAD}^{+}$, the presence of oxygen will also reduce glycerol formation. The establishment of strictly anaerobic conditions will require the addition to the medium of oxygen-trapping agents like sulphite, glucose oxidase/catalase or cysteine. Unfortunately, these agents will adversely affect the physiology of $S$. cerevisiae or hamper a quantitative treatment of the data. Hence, anaerobic conditions in bioreactor systems are normally established by sparging the bioreactor with pure nitrogen, typically in the form of commercially available nitrogen containing less than 5 p.p.m. oxygen (Schatzmann, 1975; Verduyn et al., 1990a; Visser et al., 1990, 1994). Gas of similar quality can also be produced at the site from standard nitrogen, typically containing less than 100 p.p.m. oxygen, by passing the nitrogen through a reactor filled with small copper turnings heated to $350^{\circ} \mathrm{C}$. Oxygen will be trapped in the reactor as $\mathrm{CuO}$ and the reactor can readily be regenerated by flushing with hydrogen. We compared the physiological response of $S$. cerevisiae grown in a bioreactor sparged with commercially available nitrogen containing less than 5 p.p.m. oxygen to the response obtained when using the nitrogen produced in our laboratory. We were unable to detect any differences with respect to product concentrations (data not shown).

It is well established that addition of sterols and unsaturated fatty acids to the medium is required for optimal growth of $S$. cerevisiae under strictly anaerobic conditions (Andreasen \& Stier, 1953, 1954; Verduyn et al., 1990a). However, omitting ergosterol and unsaturated fatty acids from the medium resulted in very poor growth, since less than $150 \mathrm{mg}$ biomass $\mathrm{l}^{-1}$ was produced in $24 \mathrm{~h}$ compared 
to more than $1.5 \mathrm{~g} \mathrm{l}^{-1}$ in the presence of these supplements. This further indicated that the conditions were truly anaerobic. Finally, the cells were analysed for the presence of catalase activity, an enzyme known to be active even at low oxygen concentrations (Lee \& Hassan, 1986). No activity $\left(<1 \mathrm{mU} \mathrm{mg}^{-1}\right)$ of this enzyme was detected under the described conditions. Thus, it was concluded that the described approach was successful for establishing and maintaining anaerobic conditions.

\section{Formation of biomass and extracellular metabolites}

In previously published studies, the physiological effects of nitrogen starvation were studied by transferring cells from a nitrogen-containing to a nitrogen-free medium. This was done by collecting exponentially growing cells from a shake-flask culture on a filter, followed by washing and resuspension of the cells in a nitrogen-free medium (Johnston et al., 1977b; Lagunas \& Ruiz, 1988). Such a procedure will not be suitable for studying the effects of nitrogen starvation under anaerobic conditions since the cells inevitably will be exposed to air. However, by designing the medium such that the nitrogen source becomes depleted while there is still ample glucose left in the medium, the experiment can be performed in a bioreactor without transfer of cells. Additionally, these conditions will better mimic those which can be encountered in industrial processes and the large volume of the bioreactor will allow for an intensive monitoring of both intra- and extracellular metabolites. The results of such a batch cultivation are shown in Fig. 2. Fig. 2(a) shows the concentration profile of biomass and ammonia and the CER during the cultivation, whereas the concentration profiles of the other extracellular metabolites are shown in Fig. 2(b,c). Based on these data, the cultivation could be divided into four phases.

Phase I (0-5 h) - lag phase. No detectable changes could be determined in any of the measured metabolites. The bioreactor was inoculated with S. cerevisiae CBS 8066 to an initial biomass concentration of $1 \mathrm{mg} \mathrm{l^{-1 }}$ at $t=0 \mathrm{~h}$. By extrapolating the exponential growth in phase II back to the initial biomass concentration, the length of the lag phase can be estimated at $5 \mathrm{~h}$. This relatively long lag phase is most likely due to the preculture, which was grown in an unbaffled shake flask which corresponds to aerobic growth, although severely oxygen limited. It is well known that the transfer from aerobic to anaerobic conditions will require adaptation of the cell machinery (Luzikov et al., 1970).

Phase II (5-20 h) - exponential growth phase. From Fig. 2 (a) it is seen that the culture grew exponentially until $t=20 \mathrm{~h}$. The maximum specific growth rate $\left(\mu_{\max }\right)$ determined by on-line flow injection analysis of biomass (Benthin et al,, 1991a) was found to be $0.46 \mathrm{~h}^{-1}$ (RSD $=$ $1.5 \%, n=5$ ), which was identical to the value also found for aerobic conditions ( $\mathrm{RSD}=1.5 \%, n=4)$. Thus, the presence or absence of oxygen does not affect the $\mu_{\max }$ of $S$. cerevisiae CBS 8066. At $t=20 \mathrm{~h}$, ammonia became depleted and the CER dropped sharply by more than $30 \%$. The effect of the total consumption of the extra-

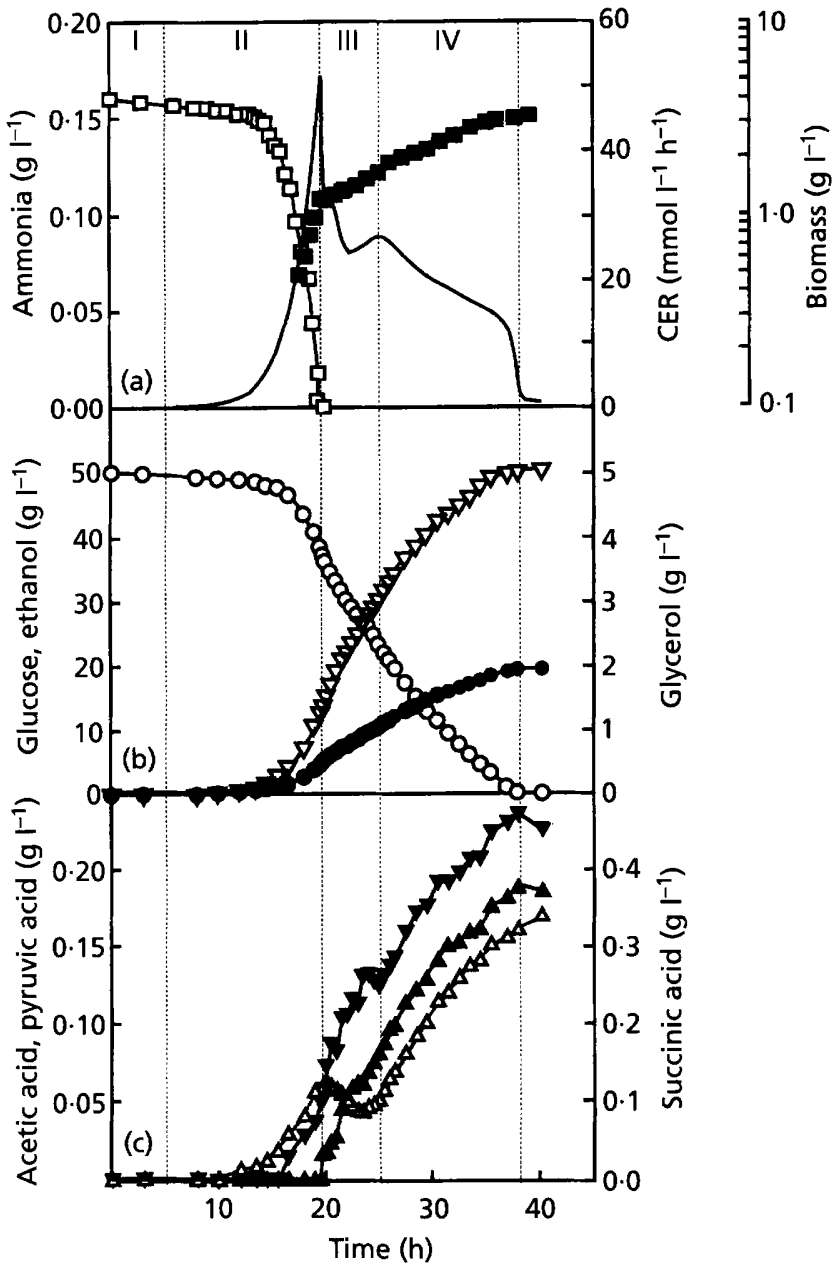

Fig. 2. (a) CER (solid line) and the concentration of biomass ( $\square$ ) and ammonia ( $\square$ ) in an anaerobic batch culture. The medium

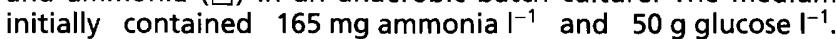
Nitrogen starvation sets in at $20 \mathrm{~h}$. (b) Concentrations of glucose $(O)$, ethanol $(\bullet)$ and glycerol $(\nabla) ;(c)$ concentrations of acetic acid $(\Delta)$, succinic acid $(\boldsymbol{\Delta})$ and pyruvic acid $(\boldsymbol{\nabla})$.

cellular ammonia was also reflected in the other concentration profiles: the exponential growth of the biomass ceased and the rates of ethanol and glycerol production were reduced as judged from Fig. 2(b). From analysis of non-nitrogen-limited cultures, it is found that both succinic acid and acetic acid are produced during the exponential growth phase, but in this experiment the concentrations were below the detection limit of the analysis.

Phase III (20-25 h) - transition phase. A highly transient course of the CER and the acetate concentration were observed. Initially the CER decreased, but at approximately $22 \mathrm{~h}$ an increase in CER was observed. The acetate concentration decreased by more than $30 \%$ during the first $3 \mathrm{~h}$ of this phase, followed by an incipient increase. The local minimum of the acetate concentration did not seem to coincide with the local minimum in the CER. The biomass concentration and the concentration of the other 
Table 1. Yields of key metabolites in various phases of the nitrogen-starved batch culture

The yields have been added up and it is seen that more than $98 \%$ of the glucose can be accounted for by the measured metabolites.

\begin{tabular}{|c|c|c|c|c|c|c|c|c|c|}
\hline \multirow[t]{2}{*}{ Phase } & \multicolumn{9}{|c|}{ Yield $\left(\mathrm{g} \mathrm{g}^{-1}\right)$} \\
\hline & Glucose & Ethanol & $\mathrm{CO}_{2}$ & Glycerol & Biomass & $\begin{array}{l}\text { Succinic } \\
\text { acid }\end{array}$ & $\begin{array}{c}\text { Pyruvic } \\
\text { acid }\end{array}$ & $\begin{array}{l}\text { Acetic } \\
\text { acid }\end{array}$ & Sum \\
\hline Phase I + II & -1.000 & $0 \cdot 382$ & 0.385 & $0 \cdot 111$ & 0.092 & 0.002 & $0 \cdot 005$ & 0.004 & -0.019 \\
\hline Phase III + IV & $-1 \cdot 000$ & $0 \cdot 391$ & $0 \cdot 419$ & $0 \cdot 097$ & $0 \cdot 055$ & $0 \cdot 009$ & $0 \cdot 004$ & 0.003 & -0.022 \\
\hline
\end{tabular}

products increased but at reduced rates compared to phase II. The glucose consumption rate was also reduced. Microscopy of the cells at the end of this phase showed that more than $80 \%$ existed as single cells.

Phase IV (25-38 h) - nitrogen-starvation phase. The linear increase in CER observed in the last part of phase III turned to a continuous decrease at the beginning of this phase. At approximately $38 \mathrm{~h}$, the CER decreased sharply to zero as a consequence of glucose depletion. The rate of glucose consumption seemed to decrease continuously during this phase and this was also reflected in a decreasing production rate of extracellular metabolites and biomass. At the end of the cultivation, virtually all $(>98 \%)$ cells existed as single cells as judged by microscopy.

Table 1 summarizes the overall yields from phase I plus II and phase III plus IV. It is seen that the biomass and the measured metabolites can account for approximately $98 \%$ of the consumed glucose. Thus, it can be concluded that no major product(s) are formed which are not accounted for by the measurements. It is seen that approximately equal amounts of glucose are used for production of ethanol $\left(Y_{\text {se }} \approx 0.39 \mathrm{~g} \mathrm{~g}^{-1}\right)$ and carbon dioxide $\left(Y_{\text {sc }} \approx\right.$ $\left.0.40 \mathrm{~g} \mathrm{~g}^{-1}\right)$. This is reasonable, since production of ethanol from pyruvate involves a decarboxylation (Fig. 1). It is observed that the experimentally determined $Y_{\mathrm{se}}$ is approximately $20 \%$ lower than the maximum theoretical yield, $Y_{\text {se }}=0.51 \mathrm{~g} \mathrm{~g}^{-1}$, which of course is due to the formation of biomass and other products. Both yields increase slightly in phase III plus IV. In phase I plus II, the yields of glycerol $\left(Y_{\text {sgly }}\right)$ and biomass $\left(Y_{\text {sx }}\right)$ are almost identical but both $Y_{\mathrm{sx}}$ and $Y_{\mathrm{sgly}}$ decrease in the phase with nitrogen starvation. In phase III plus IV, the nitrogen source is depleted and no more net synthesis of nitrogencontaining compounds can take place. $Y_{\text {sgly }}$ is therefore expected to be lower than during exponential growth, since glycerol is formed to compensate for the NADH formed in biosynthesis. However, $Y_{\text {sgly }}$ is not reduced to the same extent as $Y_{\text {sx }}$.

\section{Relationship between biomass and glycerol formation}

By plotting the amount of glycerol which is due to secretion of organic acids versus the total glycerol concentration in the medium (Fig. 3), it is possible to obtain a more detailed picture of the relationship between

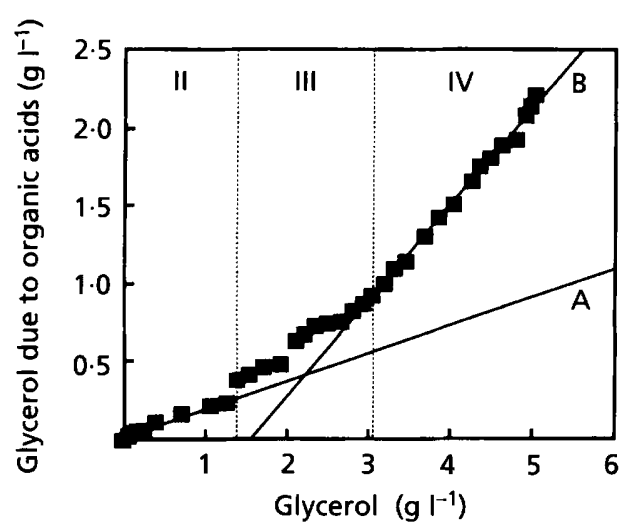

Fig. 3. Glycerol formation which can be accounted for by the formation of organic acids plotted versus the measured glycerol concentration. The slope of line A is 0.18 and that of line $B$ is 0.63 .

glycerol formation and biomass synthesis. In the calculations, it is assumed that secretion of pyruvic acid, acetic acid and succinic acid leads to production of 1,2 and $5 \mathrm{~mol} \mathrm{NADH}$ per mol acid secreted, respectively (these figures are based on the assumption that both isocitrate dehydrogenase and acetaldehyde dehydrogenase use $\mathrm{NAD}^{+}$as cofactor). Each mol NADH formed must be disposed of by formation of 1 mol glycerol. Fig. 3 illustrates that in phase II, $18 \%$ of the formed glycerol is due to secretion of organic acids, whereas secretion of organic acids accounts for $63 \%$ in phase IV. Phase III is an intermediate phase in the change from biomass synthesis to acid secretion as the major source of glycerol formation. In other words, in the presence of an extracellular nitrogen source, biomass formation accounts for more than $80 \%$ of the formed glycerol, but under nitrogen starvation less than one-third of the formed glycerol can be ascribed to processes other than acid secretion. Since the total cellular protein and RNA content remained constant during the nitrogen-starvation phase (see section on cellular composition), net synthesis of these compounds cannot explain the $37 \%$ of the glycerol formation which is not due to acid secretion.

The overall redox balance closed in each phase of the batch cultivation (Schulze, 1995), and this indicates that there is a transfer of electrons from NADH to NADPH. 
Since there is no transhydrogenase in S. cerevisiae (Lagunas \& Gancedo, 1973; van Dijken \& Scheffers, 1986), this electron transfer must be a result of protein turnover, i.e. the degradation and resynthesis of protein. However, this would require that different cofactors (NADH/NADPH) are used in degradation and resynthesis, since a net formation of NADH must take place. From the biochemistry, it is known that de novo synthesis of $1 \mathrm{~g}$ protein leads to the formation of $21.9 \mathrm{mmol} \mathrm{NADH}$ and the consumption of $15.2 \mathrm{mmol}$ NADPH (Bruinenberg et al., 1983; Verduyn et al., 1990a; Schulze, 1995). If NADPH is used in the degradation pathways where NADH was formed in the synthesis, protein turnover will result in a net synthesis of $\mathrm{NADH}$. Unfortunately, the cofactor specificity of the reactions involved in the degradation of protein is rather poorly described in the literature (Jones \& Fink, 1982; Cooper, 1982). However, in mammalian cells, degradation of alanine to pyruvate gives rise to formation of $\mathrm{NADH}$, whereas the synthesis of alanine uses NADPH as electron donor (Stryer, 1988). During phase IV, glycerol formation of $0.804 \mathrm{mmol} \mathrm{l}^{-1} \mathrm{~h}^{-1}$ is observed, which can account for de novo synthesis of $36.9 \mathrm{mg}$ protein $\mathrm{1}^{-1} \mathrm{~h}^{-1}$, corresponding to a $6 \% \mathrm{~h}^{-1}$ turnover of the protein in the cells. This calculation is based on the assumption that no NADH is used in the degradation of protein. The amino acid composition of the protein did not change significantly during the period of starvation as compared to the exponential growth phase (data not shown).

\section{Carbon dioxide evolution and the uptake of glucose}

The abrupt decrease in the CER observed simultaneously with depletion of ammonia in the medium may indicate that ammonia exerts some type of regulation on the flux through glycolysis. This abrupt decrease in the CER was also observed by Lagunas \& Ruiz (1988) in a similar experiment and was ascribed to the function of ammonia as an allosteric activator of both phosphofructokinase 1 and 2 (Ramaiah, 1974) and pyruvate kinase (Rhodes $e$ t al., 1986). However, the sudden decrease in CER may also reflect the fact that the cellular requirement for ATP of non-growing cells is lower than for growing cells.

The steady decrease in CER observed during phase IV seems to be correlated with a decrease in the glucoseuptake rate, as judged from Fig. 2(b). By plotting the rate of glucose uptake, based on the total cellular content of nitrogen, as a function of time, it is seen that the rate of glucose uptake decreases exponentially (Fig. 4). The rate constant for the decay in the uptake of glucose is $0.05 \mathrm{~h}^{-1}$, corresponding to a half-life of $13 \mathrm{~h}$ or $7 \mathrm{~h}$ if the glucoseuptake rate is expressed with respect to the biomass concentration (data not shown). A half-life of $10 \mathrm{~h}$ has previously been reported by Cardoso \& Leão (1992), but lower half-lives of between 4 and $7 \mathrm{~h}$, based on protein, have also been reported (Lagunas et al., 1982; Riballo \& Lagunas, 1994). The differences between reported values may be partly attributed to strain dependence, but may also be caused by the different methods used for measuring the glucose-uptake rate. The short half-lives were obtained from uptake-rate measurements with xylose, in

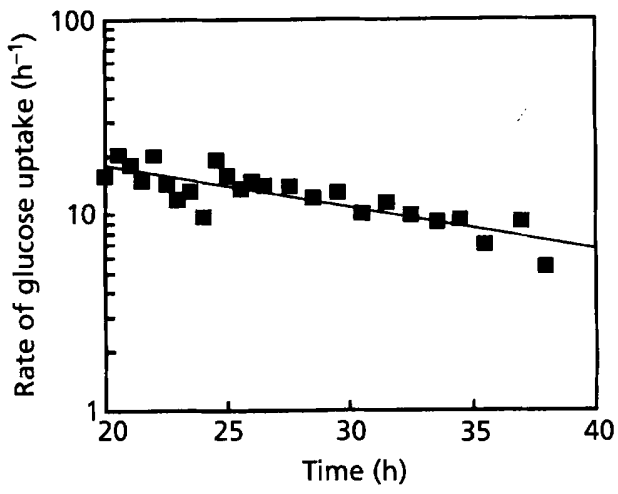

Fig. 4. Half-life of the glucose carrier. The glucose-uptake rate was expressed based on the cellular nitrogen content. If the cellular protein content is used as the basis, a half-life of $7 \mathrm{~h}$ can be calculated.

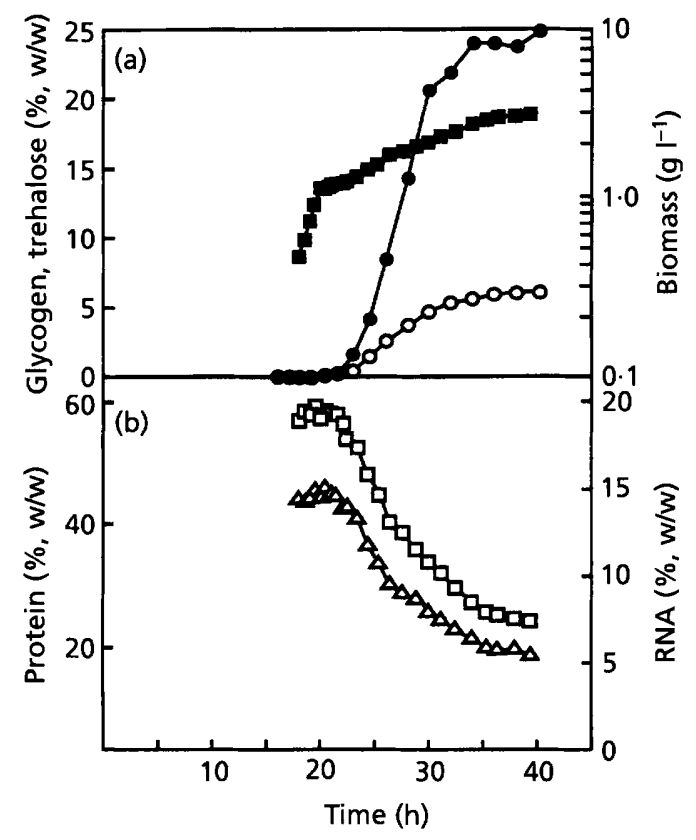

Fig. 5. (a) Biomass concentration ( $\square$ ) and the cellular content of the reserve carbohydrates trehalose (O) and glycogen (O) for the cultivation shown in Fig. 2. (b) Cellular content of protein $(\square)$ and RNA $(\triangle)$.

which case it could not be excluded that mainly the inactivation of the high-affinity transport system was determined (Busturia \& Lagunas, 1986).

\section{Cellular composition and intracellular metabolites}

The cellular composition was analysed with respect to the cellular content of trehalose, glycogen, RNA and protein. The cellular content of trehalose and glycogen is shown in Fig. 5(a) and the cellular content of protein and RNA is shown in Fig. 5(b). It was not possible to follow the cellular composition during phase I due to the low biomass concentration. 
Phase II (5-20 h). The culture grew exponentially at the highest possible growth rate, $\mu_{\max }$. The cells had a cellular protein content of $57 \%(\mathrm{w} / \mathrm{w})$ (Fig. 5b), which remained constant during the exponential phase, and the cellular content of RNA also stayed constant at $15 \%(\mathrm{w} / \mathrm{w})$ during this phase (Fig. 5b). This illustrates that the amounts of RNA and protein increased exponentially at a rate equal to $\mu_{\max }$. This phenomenon is often referred to as balanced growth (Ingraham et al., 1983). If the amount of nitrogen taken up from the medium is plotted against the biomass formed, one obtains a straight line with a slope of $0.12 \mathrm{~g} \mathrm{~g}^{-1}$ (graph not shown). This shows that the cells, at this very high growth rate, have a cellular nitrogen content of $12 \%(\mathrm{w} / \mathrm{w})$. The elemental composition of protein is $\mathrm{CH}_{1 \cdot 58} \mathrm{O}_{0 \cdot 31} \mathrm{~N}_{0 \cdot 27} \mathrm{~S}_{0 \cdot 004}$ and that of RNA is $\mathrm{CH}_{1 \cdot 23} \mathrm{O}_{0 \cdot 75} \mathrm{~N}_{0.38} \mathrm{P}_{0 \cdot 11}$ (Nielsen \& Villadsen, 1994), and by using the measured cellular content of RNA and protein, the cellular nitrogen content is calculated to be $11.9 \%(w / w)$. Hence the major part of the cellular nitrogen is bound in these two macromolecular pools. The remaining nitrogen is found in DNA, the pool of free amino acids and other nitrogen-containing compounds. The cellular content of the two carbohydrates trehalose and glycogen is virtually zero in this phase (Fig. 5a).

Phase III (20-25 h). As soon as the extracellular nitrogen source was depleted, the intracellular concentrations of glycogen and trehalose started to increase simultaneously, but with a higher rate for glycogen (Fig. 5a). The RNA content, on the other hand, started to decrease right after depletion of ammonia in the medium (Fig. 5b). However, the total amount of RNA remained constant, implying that the RNA content of the cells decreased as a consequence of an increase in the cell weight due to accumulation of glycogen and trehalose. The same applies for the protein content of the cells (Fig. 5b).

Phase IV (25-38 h). Trehalose and glycogen continued to accumulate during this phase, albeit at a decreasing rate towards the end of the cultivation. Accumulation ceased when the extracellular glucose became depleted. Throughout this phase, the cellular RNA and protein content decreased continuously as a consequence of the accumulation of intracellular carbohydrates. The total amounts of these macromolecular pools remained constant in this phase, except for the last $5 \mathrm{~h}$, when an approximate $10 \%$ decrease was observed in the cellular content of both. The amino acid composition of the cellular protein in the exponential growth phase was not significantly different from that at the end of the cultivation. No amino acid concentration changed by more than $20 \%$ (data not shown).

\section{Growth energetics}

Following the onset of nitrogen starvation, the glucose consumption continued, but the biomass concentration increased at a much slower rate (Fig. 2b, c). Thus, the cost of biomass formation in terms of ATP, $Y_{\text {xATP, increased }}$ as a consequence of nitrogen starvation. When calculating $Y_{\mathrm{xATP}}$, it is important to correct for the amount of ATP consumed in the formation of glycerol (Verduyn et al., 1990a). Typically, the energy consumption in terms of ATP is split in two terms, growth associated and nongrowth associated (Benthin et al., 1994). However, in the present case, $Y_{\mathrm{xATP}}$ can be calculated without this distinction and as mean values for the various growth phases. During the exponential growth phase, the mean value of $Y_{\mathrm{xATP}}$ was $80 \mathrm{mmol} \mathrm{g}^{-1}$, which is considerably higher than the theoretical value of $Y_{\mathrm{xATP}}$ which can be calculated from the biochemistry and cellular composition to be approximately $36 \mathrm{mmol} \mathrm{g}^{-1}$ (Verduyn et al., 1991; Schulze, 1995). Nitrogen starvation led to a $70 \%$ increase in the cost of biomass formation, resulting in a $Y_{\mathrm{xATP}}$ of $137 \mathrm{mmol} \mathrm{g}^{-1}$ in phase IV. The discrepancy between the theoretically calculated and experimentally determined values of $Y_{\mathrm{xATP}}$ becomes even larger when considering that much of the biomass increase during nitrogen starvation is due to accumulation of reserve carbohydrates. These can be synthesized at a cost of $12 \cdot 3 \mathrm{mmol} \mathrm{g}^{-1}$.

\section{DISCUSSION}

\section{Anaerobicity in bioreactors}

The supplementary addition of unsaturated fatty acids and sterols to the medium is necessary for optimal growth of S. cerevisiae (Andreasen \& Stier, 1953, 1954; Verduyn et al., 1990a), since oxygen is required in the biosynthesis of these compounds (Hunter \& Rose, 1971). However, growth in the absence of these supplements has been reported in both batch (Macy \& Miller, 1983) and continuous (Verduyn et al., 1990a) cultures. Macy \& Miller (1983) reported that $S$. cerevisiae could grow under strictly anaerobic conditions even in the absence of these compounds, although growth was slow and associated with long lag phases and low biomass yields. The medium contained the reducing agent cysteine $(0.03 \%, \mathrm{w} / \mathrm{w})$ and the colour redox indicator resazurin, which is colourless for redox potentials less than $-42 \mathrm{mV}$. The redox indicator remained colourless during the growth experiment, which was interpreted by the authors as a proof of strict anaerobic conditions at all times. However, a redox indicator measures the oxygen concentration in the solution and, as pointed out by Visser et al. (1990), it is the oxygen flux that is important for maintaining anaerobic conditions. Visser et al. (1990) showed that it is possible to have a decolourized resazurin solution and still not have anaerobic conditions. The affinity for oxygen may be very high and the oxygen-uptake rate of the micro-organism can therefore be sufficient to maintain a very low dissolved oxygen concentration, despite a continuous oxygen transfer to the solution. That growth can be observed in the absence of sterols and unsaturated fatty acids does not indicate that oxygen is dispensable in the synthesis of these compounds but merely demonstrates how difficult it is to prevent even minute amounts of oxygen from entering bioreactor systems. The absence of catalase activity was taken as an indication that anaerobic conditions prevailed in our bioreactor. In addition, this indicated that the nitrogen gas produced at site is comparable to commercial nitrogen gas containing less than 5 p.p.m. oxygen. 


\section{Exponential growth under anaerobic conditions}

In the present work, it was found that the $\mu_{\max }\left(0.46 \mathrm{~h}^{-1}\right)$ of $S$. cerevisiae was identical for aerobic and anaerobic growth. In a previous study, the anaerobic $\mu_{\max }$ of $S$. cerevisiae CBS 8066 was estimated to be $0.31 \mathrm{~h}^{-1}$ from a Hanes plot of the residual glucose concentration in a glucose-limited continuous culture (Verduyn et al., 1990a) and thus was not directly measured. It was also reported that no steady state could be obtained for dilution rates higher than $0.28 \mathrm{~h}^{-1}$. There is no obvious explanation for the discrepancy, since the same medium was used and since no catalase activity could be detected in either of the cultures. However, high growth rates under anaerobic conditions have been reported: Visser et al. (1990) report that $S$. cerevisiae CBS 1171 has an anaerobic $\mu_{\max }$ of $0.40 \mathrm{~h}^{-1}$ but do not state the aerobic $\mu_{\max }$; Lagunas (1979, 1986) presents data from a shake-flask culture of $S$. cerevisiae S-13-Gal showing an anaerobic $\mu_{\max }$ which is approximately $95 \%$ of the aerobic $\mu_{\max }$. Lagunas (1979) concludes that aerobiosis as compared to anaerobiosis does not provide $S$. cerevisiae with an energetic advantage that allows it to grow faster under the former conditions. The present results support the conclusion that energy generation does not seem to limit growth of $S$. cerevisiae.

\section{Formation of extracellular metabolites}

The fact that glycerol formation is due to a redox imbalance has been recognized for a long time (Barron \& Levine, 1952; Holzer et al., 1963), but it was only by the work of Nordström $(1966,1968)$ that it became apparent that biomass formation is the major cause of glycerol formation. The results in this work show that glycerol formation is higher under conditions where biomass synthesis is unrestricted and that limitation of biomass synthesis by nitrogen starvation leads to a decrease in glycerol formation. The experimental data also illustrate that the theoretical yield of ethanol on glucose ( $Y_{\text {se }}=$ $0.51 \mathrm{~g} \mathrm{~g}^{-1}$ ) can only be approached if biomass formation and the concomitant glycerol formation are arrested, i.e. the function of the biomass should approach that of a catalyst. Since nitrogen starvation leads to decreasing yields of both biomass and glycerol and increasing yields of ethanol (Table 1), it may be tempting to conclude that such conditions are optimal for ethanol production. However, under nitrogen starvation, the rate of ethanol production will decrease with time due to catabolite inactivation of the glucose transporter (Fig. 4). Hence, long periods of nitrogen starvation should be avoided in the production of ethanol.

Each of the formed organic acids accounts for no more than $1 \%$ of the consumed glucose, but they have an important impact on the redox level in the cell (Fig. 3). Currently, the secretion of organic acids is not believed to have a direct function as, e.g. the formation of glycerol, and secretion is in most cases ascribed to leakage from the intracellular pool (Fraenkel, 1982; Gancedo \& Serrano, 1989). Both succinic acid and pyruvic acid are produced throughout the cultivation, although at decreasing rates. The reason for the transient behaviour of the acetic acid concentration at the CER in phase III remains unexplainable at the moment.

\section{Turnover of protein}

The rate of protein turnover is traditionally estimated from the release of radioactive material from labelled protein (Betz, 1976). The obtained value is a minimum estimate, since reutilization of the labelled degradation products may occur. By application of this technique, the rate of protein tumover under nitrogen starvation has been estimated to be $2 \% \mathrm{~h}^{-1}$ (López \& Gancedo, 1979), $4 \% \mathrm{~h}^{-1}$ (Johnston et al., 1977b) or $3 \% \mathrm{~h}^{-1}$ (Betz, 1976) for S. cerevisiae and 4-7\% $\mathrm{h}^{-1}$ for Escherichia coli (Mandelstam, 1958). This confirms that turnover of protein does occur under conditions of nitrogen starvation. The rate of protein turnover of $6 \% \mathrm{~h}^{-1}$ estimated in this study from the glycerol formation which cannot be ascribed to the secretion of organic acids is based on the assumption that no $\mathrm{NAD}^{+}$is formed in the degradation of protein. However, the estimated value seems reasonable, although a little high. Turnover of RNA also occurs, and although synthesis of RNA leads to formation of less NADH than the synthesis of protein $\left[6.7 \mathrm{mmol} \mathrm{NADH}(\mathrm{mol} \mathrm{RNA})^{-1}\right.$ versus $21.9 \mathrm{mmol} \mathrm{NADH}$ (mol protein $)^{-1}$ ], the turnover of e.g. mRNA is much faster than the turnover of protein. Hence, it cannot be excluded that the unaccounted for glycerol formation is connected at least partially with turnover of RNA.

\section{The effect of ammonia on the EMP pathway}

Based on in vitro experiments, it has been established that ammonia is an allosteric activator of phosphofructokinase (Ramaiah, 1974) and pyruvate kinase (Rhodes et al., 1986). Consequently, one may expect that depletion of ammonia will lead to a reduced activity of these two key enzymes and thus to a reduced flux through the EMP pathway (Fig. 2). Another explanation may be that the signalling pathway induced by fermentable growth medium is turned off due to depletion of ammonia (Thevelein, 1994). This pathway will be active as long as there is ammonia and excess glucose in the medium and will lead to an activation of enzymes through the cAMP-dependent protein kinase. Depletion of ammonia can be expected to have the opposite effect, i.e. causing deactivation of e.g. phosphofructokinase (Francois et al., 1984; Thevelein, 1994). It seems likely that depletion of ammonia triggers the abrupt decrease in the CER, but whether the mechanism is based on the direct allosteric action of ammonia or whether ammonia exerts action through a signal transduction pathway remains unclear.

\section{Catabolite inactivation of the glucose transporter(s)}

It seems likely that the continuous decrease in the CER (Fig. 2a) is due to a decrease in the uptake of glucose (Fig. 4), caused by catabolite inactivation of the glucose transporters (Lagunas et al., 1982; Busturia \& Lagunas, 1986; Riballo \& Lagunas, 1994). This is supported by the fact that the decrease in the glucose-transport rate cannot nearly be accounted for by the effect the decreasing 
extracellular glucose concentration will have on the glucose-transport rate, even if glucose was only transported by the low-affinity system with a $K_{\mathrm{m}}$ of $20-25 \mathrm{mM}$. Both the high-affinity and the low-affinity carriers are affected by the inactivation, which is the result of endocytosis (Riballo \& Lagunas, 1994). It is not the absence of ammonia per se that is the cause of inactivation but rather the arrest of protein synthesis (Busturia \& Lagunas, 1986; Alonso \& Kotyk, 1978). The inactivation requires the presence of a fermentable substrate, since inactivation was not observed during carbon starvation but was induced when sugar was added to a carbon- and nitrogen-starved culture (Busturia \& Lagunas, 1986). Addition of ammonia to ammonia-starved cells leads to reactivation of the sugar transporters, but the mechanism does not involve de novo synthesis of the sugar transporters but rather synthesis of a regulatory protein (Bely et al., 1994). Catabolite inactivation of the glucose carrier in the absence of ammonia is a great nuisance to oenology (Salmon, 1989; Mauricio \& Salmon, 1992; Salmon et al., 1993; Bely et al., 1994). Grape juices often have low concentrations of ammonia, which will lead to sluggish or stuck fermentations, i.e. very delayed or incomplete fermentations, due to the catabolite inactivation of the glucose transporter (Salmon, 1989; Salmon et al., 1993).

\section{Cellular composition}

It is well established that the cellular content of protein and RNA is proportional to the specific growth rate and that cells need a high cellular content of these macromolecules for rapid growth (Waldron \& Lacroute, 1975; Parada \& Acevedo, 1983; Verduyn et al., 1990a; Verduyn, 1992). The determined cellular content values of RNA $(15 \%, w / w)$ and protein $(57 \%, w / w)$ (Fig. $5 b)$ are in accordance with previously reported values (Waldron \& Lacroute, 1975; Verduyn et al., 1990a). Nitrogen starvation leads to a decreasing relative cellular content of both RNA and protein but the total cellular content of these macromolecules remains constant, an observation which is supported by results based on radioactively labelled RNA and protein (Johnston et al., 1977b). A large portion of the ribosomes is presumably inactive at low growth rates, as indicated by the results of Waldron $e t$ al. (1977), who showed that the fraction of ribosomes engaged in protein synthesis decreased from more than $80 \%$ at high growth rates to less than $50 \%$ in slowly growing cells. Nitrogen starvation virtually inhibits cells from reinitiating cell division but cells already engaged in cell division will complete the cell division cycle and eventually get arrested in the $G_{1}$ phase (Hartwell, 1974; Johnston et al., 1977b; Schulze, 1995).

S. cerevisiae accumulates huge quantities of intracellular carbohydrates under conditions of limitation, e.g. by nitrogen in the presence of excess glucose (Lillie \& Pringle, 1980; Slaughter \& Nomura, 1992; Quain et al., 1981). Neither trehalose nor glycogen accumulate during exponential growth (Fig. 5a), but accumulation of both carbohydrates sets in right after depletion of the extracellular nitrogen source. Both carbohydrates continue to accumulate, as long as there is glucose present in the medium, although the rate of accumulation decreases towards the end of the cultivation. The majority of the sequestrated glucose ends up as glycogen, supporting the notion that glycogen serves as a storage carbohydrate (Lillie \& Pringle, 1980; Panek, 1991). According to recent results, the functional role of trehalose is as a stress protectant rather than as an energy store (Wiemken, 1990; Eleutherio et al., 1993; van Dijck et al., 1995). This is in line with the fact that nitrogen starvation is usually considered a stress situation. Although the intracellular content of carbohydrates is very large, less than $2 \%$ of the metabolized glucose ends up as storage carbohydrates.

\section{Energetics}

The reported value of $Y_{\mathrm{xATP}}$ for the exponential growth phase $\left(80 \mathrm{mmol} \mathrm{g}^{-1}\right)$ is similar to values reported in the literature: $75-85 \mathrm{mmol} \mathrm{g}^{-1}$ in a batch cultivation (defined medium) (Haukali \& Lie, 1971) and $90 \mathrm{mmol} \mathrm{g}^{-1}$ in a glucose-limited continuous culture (defined medium) at a dilution rate of $0.28 \mathrm{~h}^{-1}$ (Verduyn et al., 1990a, b). Thus, the observation that $Y_{\mathrm{xATP}}$ is significantly higher than the theoretically calculated value of $Y_{\mathrm{xATP}}$ is well known and has also been observed for many other micro-organisms, e.g. E. coli (Hempfling \& Mainzer, 1975) and Aerobacter aerogenes (Stouthamer \& Bettenhaussen, 1976). This discrepancy is usually ascribed to futile cycles (Auberson $e t$ al., 1989; Navas et al., 1993) or dissipation of ATP by the membrane ATPases (Stouthamer, 1979). Also it has been demonstrated that the presence of weak acids may lead to a significant dissipation of ATP due to an increased influx of protons and consequently to an increase in $Y_{\mathrm{xATP}}$ (Verduyn et al., 1990b, 1992; Verduyn, 1992). However, since the concentration of weak acids is very low in phase I plus II, this specific mechanism does not seem to be a major cause of the observed difference. When the yeast becomes nitrogen starved, $Y_{\mathrm{xATP}}$ increases significantly to more than $130 \mathrm{mmol} \mathrm{g}^{-1}$. The increase in the extracellular concentration of weak acids in phase IV may partially account for this, but it seems likely that the general degree of energy dissipation increases. Results from anabolically limited cultures seem to support this notion, e.g. Benthin et al. (1994) observed that nitrogen limitation leads to a significant increase in $Y_{\mathrm{xATP}}$ for the lactic acid bacterium Lactococcus cremoris and similar results have been observed for Klebsiella aerogenes (Neijssel \& Tempest, 1976; Neijssel et al., 1990). Thus, under conditions of nitrogen starvation or limitation, $S$. cerevisiae and other micro-organisms do not seem to regulate their energy consumption to the actual needs, which is manifested in a very high $Y_{\mathrm{xATP}}$.

\section{ACKNOWLEDGEMENTS}

G. Lidén gratefully acknowledges scholarships from the Swedish Institute and the Nordic Academy for Advanced Studies.

\section{REFERENCES}

Alonso, J. \& Kotyk, A. (1978). Apparent half-lives of sugar transport proteins in Saccharomyces cerevisiae. Folia Microbiol 23, 118-125. 
Andreasen, A. A. \& Stier, T. J. B. (1953). Anaerobic nutrition of Saccharomyces cerevisiae. I. Ergosterol requirement for the growth in a defined medium. J Cell Comp Physiol 41, 23-36.

Andreasen, A. A. \& Stier, T. J. B. (1954). Anaerobic nutrition of Saccharomyces cerevisiae. II. Unsaturated fatty acid requirement for the growth in a defined medium. J Cell Comp Physiol 43, 271-281.

Auberson, L. C. M., Ramseier, C. V., Marison, I. W. \& von Stockar, U. (1989). Further evidence for the existence of a bottleneck in the metabolism of Saccharomyces cerevisiae. Experientia 45, 1013-1018.

Barron, E. S. G. \& Levine, S. (1952). Oxidations of alcohols by yeast alcohol dehydrogenase and by the living cell. The thiol groups of the enzyme. Arch Biochem Biophys 41, 175-187.

Bely, M., Salmon, J. M. \& Barre, P. (1994). Assimilable nitrogen addition and hexose transport system activity during enological fermentation. J Inst Brew 100, 279-282.

Benthin, S., Nielsen, J. \& Villadsen, J. (1991a). Characterization and application of precise and robust flow-injection analysers for online measurement during fermentations. Anal Cbim Acta 247, $45-50$.

Benthin, S., Nielsen, J. \& Villadsen, J. (1991b). A simple and reliable method for the determination of cellular RNA content. Biotechnol Tech 5, 39-42.

Benthin, S., Schulze, U., Nielsen, J. \& Villadsen, J. (1994). Growth energetics of Lactococcus cremoris FD1 during energy-, carbon-, and nitrogen-limitation in steady state and transient cultures. Chem Eng Sci 49, 589-609.

Betz, H. (1976). Inhibition of protein synthesis stimulates intracellular protein degradation in growing yeast cells. Biochem Biophys Res Commun 72, 121-130.

Bruinenberg, P. M., van Dijken, J. P. \& Scheffers, W. A. (1983). Theoretical analysis of NADPH production and consumption in yeasts. J Gen Microbiol 129, 953-964.

Busturia, A. \& Lagunas, R. (1986). Catabolite inactivation of the glucose transport system in Saccharomyces cerevisiae. J Gen Microbiol $132,379-385$

Cardoso, H. \& Leão, C. (1992). Sequential inactivation of ammonium and glucose transport in Saccharomyces cerevisiae during fermentation. FEMS Microbiol Lett 94, 155-160.

Christensen, L. H., Nielsen, J. \& Villadsen, J. (1991). Monitoring of substrates and products during fed-batch penicillin fermentations on complex media. Anal Chim Acta 249, 123-136.

Christensen, L. H., Schulze, U., Nielsen, J. \& Villadsen, J. (1995). Acoustic gas analysis for fast and precise monitoring of bioreactors. Chem Eng Sci 50, 2601-2610.

Cooper, T. G. (1982). Nitrogen metabolism in Saccharomyces cerevisiae. In The Molecular Biology of the Yeast Saccharomyces. Metabolism and Gene Expression, pp. 39-99. Edited by J. N. Strathern, E. W. Jones \& J. R. Broach. Cold Spring Harbor, NY: Cold Spring Harbor Laboratory.

van Dijck, P., Colavizza, D., Smet, P. \& Thevelein, J. M. (1995). Differential importance of trehalose in stress resistance in fermenting and nonfermenting Saccharomyces cerevisiae cells. Appl Environ Microbiol 61, 109-115.

van Dijken, J. P. \& Scheffers, W. A. (1986). Redox balances in the metabolism of sugars by yeasts. FEMS Microbiol Rev 32, 199-224.

Eleutherio, E. C. A., Araujo, P. S. \& Panek, A. D. (1993). Protective role of trehalose during heat stress in Saccharomyces cerevisiae. Cryobiology 30, 591-596.

Fraenkel, D. G, (1982). Carbohydrate metabolism. In The Molecular Biology of the Yeast Saccharomyces. Metabolism and Gene Expression, pp. 1-37. Edited by J. N. Strathern, E. W. Jones \& J. R. Broach. Cold Spring Harbor, NY: Cold Spring Harbor Laboratory.

Francois, J., van Schaftingen, E. \& Hers, H.-G. (1984). The mechanism by which glucose increases fructose-2,6-bisphosphate concentration in Saccharomyces cerevisiae. A cyclic-AMP-dependent activation of phosphofructokinase 2. Eur J Biochem 145, 187-193.

Gancedo, C. \& Serrano, R. (1989). Energy-yielding metabolism. In The Yeasts, vol. 3, Metabolism and Physiology of Yeasts, pp. 205-259. Edited by A. H. Rose \& J. S. Harrison. London: Academic Press. Genevois, L. (1950). Essais de bilans de la fermentation alcoolique due aux cellules de levures. Biocbim Biophys Acta 4, 179-192.

Genevois, L. (1961). Die Sekundärprodukte der alkoholischen Gärung. Brauwissenschaft 14, 52-55.

Hartwell, L. H. (1974). Saccharomyces cerevisiae cell cycle. Bacteriol Rev 38, 164-198.

Haukali, A. D. \& Lie, S. (1971). Molar growth yields of yeasts in anaerobic batch cultures. J Gen Microbiol 69, 135-141.

Hempfling, W. P. \& Mainzer, S. E. (1975). Effects of varying the carbon source limiting growth on yield and maintenance characteristics of Eschericbia coli in continuous culture. J Bacteriol 123, 1076-1087.

Holzer, H., Bernhardt, W. \& Schneider, S. (1963). Zur Glycerinbildung in Bäckerhefe. Biochem Z 336, 495-509.

Hunter, K. \& Rose, A. H. (1971). Yeast lipids and membranes. In The Yeasts, vol. 2, pp. 211-270. Edited by A. H. Rose \& J. S. Harrison. London: Academic Press.

Ingraham, J. L., Maaløe, O. \& Neidhardt, F. C. (1983). Growth of the Bacterial Cell. Sunderland, MA: Sinauer Associates.

Johnston, G. C. (1977). Cell size and budding during starvation of the yeast Saccharomyces cerevisiae. J Biochem Microbiol Tecbnol Eng 132, 738-739.

Johnston, G. C., Pringle, J. R. \& Hartwell, L. H. (1977a). Coordination of growth with cell division in the yeast Saccharomyces cerevisiae. Exp Cell Res 105, 79-98.

Johnston, G. C., Singer, R. A. \& McFarlane, E. S. (1977b). Growth and cell division during nitrogen starvation of the yeast Saccharomyces cerevisiae. J Bacteriol 132, 723-730.

Jones, E. W. \& Fink, G. R. (1982). Regulation of amino acid and nucleotide biosynthesis in yeast. In The Molecular Biology of the Yeast Saccharomyces. Metabolism and Gene Expression, pp. 181-299. Edited by J. N. Strathern, E. W. Jones \& J. R. Broach. Cold Spring Harbor, NY: Cold Spring Harbor Laboratory.

Lagunas, R. (1979). Energetic irrelevance of aerobiosis for $S$. cerevisiae growing on sugars. Mol Cell Biochem 27, 139-146.

Lagunas, R. (1986). Misconceptions about the energy metabolism of Saccharomyces cerevisiae. Yeast 2, 221-228.

Lagunas, R. \& Gancedo, J. M. (1973). Reduced pyridine-nucleotides balance in glucose-growing Saccharomyces cerevisiae. Eur J Biochem 37, 90-94.

Lagunas, R. \& Ruiz, E. (1988). Balance of production and consumption of ATP in ammonium-starved Saccharomyces cerevisiae. J Gen Microbiol 134, 2507-2511.

Lagunas, R., Domínguez, C., Busturia, A. \& Sáez, M. J. (1982). Mechanisms of appearance of the Pasteur effect in Saccharomyces cerevisiae: inactivation of sugar transport system. $J$ Bacteriol 152, 19-25.

Larsson, C., von Stockar, U., Marison, I. \& Gustafsson, L. (1993). Growth and metabolism of Saccharomyces cerevisiae in chemostat cultures under carbon-, nitrogen, or carbon- and nitrogen-limiting conditions. J Bacteriol 175, 4809-4816. 
Lee, F.-J. \& Hassan, H. M. (1986). Biosynthesis of superoxide dismutase and catalase in Saccharomyces cerevisiae: effects of oxygen and cytochrome c deficiency. I Ind Microbiol 1, 187-193.

Lillie, S. H. \& Pringle, J. R. (1980). Reserve carbohydrate metabolism in Saccharomyces cerevisiae: response to nutrient limitation. J Bacteriol 143, 1384-1394.

López, S. \& Gancedo, J. M. (1979). Effect of metabolic conditions on protein turnover in yeast. J Bacteriol 178, 769-776.

Luzikov, V. N., Zubatov, A. S. \& Rainina, E. I. (1970). Degradation of mitochondrial respiratory system of Saccharomyces cerevisiae, induced by respiratory inhibitors, uncouplers and anaerobiosis. FEBS Lett 11, 233-236.

Macy, J. M. \& Miller, M. W. (1983). Anaerobic growth of Saccharomyces cerevisiae in the absence of oleic acid and ergosterol? Arch Microbiol 134, 64-67.

Mandelstam, J. (1958). Turnover in growing and non-growing populations of Escherichia coli. Biochem J 69, 110-119.

Mauricio, J. C. \& Salmon, J. M. (1992). Apparent loss of sugar transport activity in Saccbaromyces cerevisiae may mainly account for maximum ethanol production during alcoholic fermentation. Biotechnol Lett 14, 577-582.

Navas, M. A., Cerdán, S. \& Gancedo, J. M. (1993). Futile cycles in Saccharomyces cerevisiae strains expressing gluconeogenic enzymes during growth on glucose. Proc Natl Acad Sci US A 90, 1290-1294.

Neijssel, O. M. \& Tempest, D. W. (1976). Bioenergetic aspects of aerobic growth of Klebsiella aerogenes NCTC 418 in carbon-limited and carbon-sufficient chemostat cultures. Arcb Microbiol 107, 215-221

Neijssel, O. M., Buurman, E. T. \& Teixeira de Mattos, M. J. (1990). The role of futile cycles in the energetics of bacterial growth. Biocbim Biophys Acta 1018, 252-255.

Nielsen, J. \& Villadsen, J. (1994). Bioreaction Engineering Principles. New York: Plenum Press.

Nordström, K. (1966). Yeast growth and glycerol formation. Acta Chem Scand 20, 1016-1025.

Nordström, K. (1968). Yeast growth and glycerol formation. II. Carbon and redox balances. J Inst Brew 74, 429-432.

Oura, E. (1977). Reaction products of yeast fermentations. Process Biochem 12, 19-21, 35.

Panek, A. D. (1991). Storage carbohydrates. In The Yeasts, vol. 4, Yeast Organelles, pp. 655-678. Edited by A. H. Rose \& J.S. Harrison. London: Academic Press.

Parada, G. \& Acevedo, F. (1983). On the relation of temperature and RNA content to the specific growth rate in Saccharomyces cerevisiae. Biotechnol Bioeng 25, 2785-2788.

Postma, E., Verduyn, C., Scheffers, W. A. \& van Dijken, J.P. (1989). Enzymic analysis of the crabtree effect in glucose-limited chemostat cultures of Saccharomyces cerevisiae. Appl Environ Microbiol 53, 468-477.

Quain, D. E., Thurrston, P. A. \& Tub, R. S. (1981). The structural and storage carbohydrates of Saccbaromyces cerevisiae: changes during fermentation of wort and a role for glycogen metabolism in lipid synthesis. J Inst Brew 87, 108-111.

Ramaiah, A. (1974). Pasteur effect and phosphofructokinase. Curr Top Cell Regul 8, 297-345.

Rhodes, N., Morris, C. N., Ainsworth, S. \& Kinderlerer, J. (1986). The regulatory properties of yeast pyruvate kinase. Effects of $\mathrm{NH}_{4}{ }^{+}$ and $\mathrm{K}^{+}$concentrations. Biochem $J$ 234, 705-715.

Riballo, E. \& Lagunas, R. (1994). Involvement of endocytosis in catabolite inactivation of the $\mathrm{K}^{+}$and glucose transport systems in Saccharomyces cerevisiae. FEMS Microbiol Lett 121, 77-80.
Salmon, J. M. (1989). Effect of sugar transport inactivation in Saccharomyces cerevisiae on sluggish and stuck enological fermentations. App/ Environ Microbiol 55, 953-958.

Salmon, J. M., Vincent, O., Mauricio, J. C., Bely, M. \& Barre, P. (1993). Sugar transport inhibition and apparent loss of activity in Saccbaromyces cerevisiae as a major limiting factor of enological fermentations. Am J Enol Vitic 44, 56-63.

Schatzmann, H. (1975). Anaerobes Wachstum von Saccharomyces cerevisiae. Regulatorische Aspekte des glycolytischen und respirativen Stoffwechsels. $\mathrm{PhD}$ thesis no. 5504, ETH, Zurich.

Schulze, U. (1995). Anaerobic physiology of Saccharomyces cerevisiae. PhD thesis, Department of Biotechnology, The Technical University of Denmark, Denmark.

Schulze, U., Larsen, M. E. \& Villadsen, J. (1995). Determination of intracellular trehalose and glycogen in Saccharomyces cerevisiae. Anal Biochem 228, 143-149.

Slaughter, J. C. \& Nomura, T. (1992). Intracellular glycogen and trehalose contents as predictors of yeast viability. Enzyme Microb Tecbnol 14, 64-67.

Stouthamer, A. H. (1979). The search for correlation between theoretical and experimental growth yields. Microbiol Biochem 21, $1-47$.

Stouthamer, A. H. \& Bettenhaussen, C. (1976). Energetic aspects of anaerobic growth of Aerobacter aerogenes in complex medium. Arcb Microbiol 111, 21-23.

Stryer, L. (1988). Biochemistry, 3rd edn. New York: Freeman.

Thevelein, J. M. (1994). Signal transduction in yeast. Yeast 10, 1753-1790.

Verduyn, C. (1992). $Y_{x A T P}$ and $P / O$ in glucose-limited chemostat cultures of Saccharomyces cerevisiae. In Energetic aspects of metabolic fluxes in yeasts, pp. 70-84. PhD thesis, Technical University of Delft, The Netherlands.

Verduyn, C., van Dijken, J. P. \& Scheffers, W. A. (1984). Colorimetric alcohol assay with alcohol oxidase. J Microbiol Methods 2, $15-25$.

Verduyn, C., Postma, E., Scheffers, W. A. \& van Dijken, J.P. (1990a). Physiology of Saccharomyces cerevisiae in anaerobic glucoselimited chemostat cultures. J Gen Microbiol 136, 395-403.

Verduyn, C., Postma, E., Scheffers, W. A. \& van Dijken, J.P. (1990b). Energetics of Saccharomyces cerevisiae in anaerobic glucoselimited chemostat cultures. J Gien Microbiol 136, 405-412.

Verduyn, C., Stouthamer, A. H., Scheffers, W. A. \& van Dijken, J.P. (1991). A theoretical evaluation of growth yields of yeasts. Antonie Leeuwenhoek 59, 49-63.

Verduyn, C., Postma, E., Scheffers, W. A. \& van Dijken, J. P. (1992). Effect of benzoic acid on metabolic fluxes in yeast: a continuous culture study on the regulation of respiration and alcoholic fermentation. Yeast 8, 501-517.

Visser, W., Scheffers, W. A., Batenburg-van der Vegte, W. H. \& van Dijken, J.P. (1990). Oxygen requirements of yeast. Appl Environ Microbiol 56, 3785-3792.

Visser, W., van der Baan, A. A., Batenburg-van der Vegte, W., Scheffers, W. A., Krămer, R. \& van Dijken, J. P. (1994). Involvement of mitochondria in the assimilatory metabolism of anaerobic Saccharomyces cerevisiae. Microbiology 140, 3039-3046.

Visser, W., van Spronsen, E. A., Nanninga, N., Pronk, J. T., Kuenen, J. G. \& van Dijken, J.P. (1995). Effects of growth conditions on mitochondrial morphology in Saccharomyces cerevisiae. Antonie Leewnenboek 67, 243-253. 
Waldron, C. \& Lacroute, F. (1975). Effect of growth rate on the amount of ribosomal and transfer ribonucleic acids in yeast. J Bacteriol 122, 855-865.

Waldron, C., Jund, R. \& Lacroute, F. (1977). Evidence for a high proportion of inactive ribosomes in slow-growing yeast cells. Biocbem J 168, 409-415.
Wiemken, A. (1990). Trehalose in yeast, stress protectant rather than reserve carbohydrate. Antonie Leeuwenboek 58, 209-217.

Received 9 November 1995; revised 12 February 1996; accepted 7 March 1996. 